\title{
Polylabris lingaoensis sp. n. and Polylabris cf. mamaevi Ogawa et Egusa, 1980 (Monogenoidea: Microcotylidae) from perciform fishes in the Gulf of Tonkin, South China Sea
}

\author{
Yang Tingbao ${ }^{1}$, Delane C. Kritsky ${ }^{2}$ and Pan Jun ${ }^{1}$ \\ ${ }^{1}$ Institute of Aquatic Economic Animals and the Key Laboratory of Guangdong Province for Improved Reproduction of \\ Economic Animals, Zhongshan University, Ghangzhou 510275, China; \\ ${ }^{2}$ Department of Health and Nutrition Sciences, College of Health Professions, Campus Box 8090, Idaho State University, \\ Pocatello, Idaho 83209, USA
}

Key words: Monogenoidea, Microcotylidae, Polylabris, Polylabris lingaoensis, Polylabris cf. mamaevi, Ambassis gymnocephalus, Siganus fuscescens, South China Sea, China

\begin{abstract}
Polylabris lingaoensis sp. $\mathrm{n}$. is described from the gills of the bald glassy, Ambassis gymnocephalus (Chandidae), from the Gulf of Tonkin (South China Sea), near Lingao, Hainan Province, China. The new species is characterized by a midventral vaginal pore, comparatively few (5-7) testes, and 2 parallel rows each comprised of 30-43 microcotylid clamps in the haptor. Polylabris lingaoensis is the only member of the genus known to parasitize a chandid host. Polylabris cf. mamaevi is described from the gills of the mottled spinefoot, Siganus fuscescens (Siganidae), from the South China Sea, which represents new host and locality records for the helminth. The gill parasites from S. fuscescens are tentatively assigned to P. mamaevi pending new collections and restudy of microcotylid species from siganid fishes.
\end{abstract}

Hayward (1996), in his revision of Polylabris Euzet et Cauwet, 1967 (Microcotylidae, Prostatomicrocotylinae), recognized 17 valid species: P. acanthogobii (Yamaguti, 1940) Mamaev et Parukhin, 1976 from Acanthogobius flavimanus (Temminck et Schlegel) (Gobiidae); P. acanthopagri Mamaev et Parukhin, 1976 from Acanthopagrus bifasciatus (Forsskål) (Sparidae); P. angifer Hussey, 1986 from A. latus (Houttuyn) (Sparidae); P. australiensis Hayward, 1996 from Sillago schomburgkii Peters and S. analis Whitley (both Sillaginidae); P. carnarvonensis Dillon, Hargis et Harrises, 1983 from Leiognathus fasciatus (Lacépède) (Leiognathidae); P. gerres (Sanders, 1944) Mamaev et Parukhin, 1976 from Gerres subfasciatus $\mathrm{Cu}-$ vier and G. oyena (Forsskål) (both Gerreidae); P. girellae Hayward, 1996 from Girella tricuspidata (Quoy et Gaimard) (Kyphosidae); P. japonicus Ogawa et Egusa, 1980 from A. schlegelii (Bleeker) (Sparidae); P. kuhliae (Yamaguti, 1968) Mamaev et Parukhin, 1976 from Kuhlia sandvicensis (Steindachner) (Kuhliidae); P. madagascarensis Hayward, 1996 from $S$. sihama (Forsskål) (a questionable host identification; see Hayward 1996) (Sillaginidae); $P$. maomao (Yamaguti, 1968) Mamaev et Parukhin, 1976 from Abudefduf abdominalis (Quoy et Gaimard) (Pomacentridae); P. queenslandensis Hayward, 1996 from $S$. analis, S. ciliata Cuvier, S. maculata Quoy et Gaimard and $S$. sihama (all Sillaginidae); P. rhabdosargi Hayward, 1996 from Rhabdosargus sarda (Forsskål) (Sparidae); $P$. sigani Dillon, Hargis et Harrises, 1983 from Siganus oramin (Bloch et Schneider) [valid name, Siganus canaliculatus (Park)] (Siganidae); P. sillaginae (Woolcock,
1936) Dillon, Hargis et Harrises, 1983 from Sillaginodes punctatus (Cuvier), Sillago bassensis Cuvier, S. burrus Richardson, S. ciliata, S. maculata, S. schomburgkii (identity of host questioned by Hayward 1996), S. aeolus Jordan et Evermann, $S$. flindersi McKay, $S$. robusta Stead, $S$. sihama and S. ingenuua McKay (all Sillaginidae); P. tubicirrus (Paperna et Kohn, 1964) Mamaev et Parukhin, 1976 from Diplodus annularis (Linnaeus), D. sargus (Linnaeus), D. vulgaris (Geoffroy Saint-Hilaire), D. c. cervinus (Lowe), D. puntazzo (Cetti), D. argenteus (Valenciennes), Sparus aurata Linnaeus and Oblada melanura (Linnaeus) (all Sparidae); and P. williamsi Hayward, 1996 from $S$. analis and S. schomburgkii (both Sillaginidae). Hayward (1996) considered $P$. indica Hayward, 1996 (= Bivagina sillaginae of Gupta and Khullar 1968) from Chelon macrolepis (Smith) [valid name, Liza macrolepis (Smith)] (Mugilidae), P. mamaevi Ogawa et Egusa, 1980 from Siganus stellatus (Forsskål) (Siganidae), and $P$. virgatarum (Tubangui, 1931) Mamaev, 1986 from S. virgatus (Valenciennes) (Siganidae), to be species inquirendae. Mamaev and Parukhin (1976) also reported P. mamaevi (as P. gerres) from Siganus oramin (Siganidae), and Terapon jarbua (Forsskål) (Terapontidae), but Ogawa and Egusa (1980) were uncertain whether or not these forms were conspecific with the form from S. stellatus. Polylabris diplodi Euzet et Cauwet, 1967, type species of the genus, was placed in subjective junior synonymy with $P$. tubicirrus by Santos et al. (1996). Polylabris halichoeres Wang et Zhang, 1998 was subsequently described from Halichoeres nigrescens (Bloch et Schneider) (Labridae) 
from China by Wang and Zhang (1998). Finally, the assignment of Atriaster heterodus Lebedev et Parukhin, 1969 (Microcotylidae, Atriasterinae) to Polylabris by Mollaret et al. (2000) is erroneous (J.-L. Justine, pers. comm.). To date, species of Polylabris have been reported from the gills of members of 11 families of marine perciform fishes.

During an investigation of the monogenoidean fauna of fishes in the South China Sea, a new species of Polylabris from the gills of the bald glassy, Ambassis gymnocephalus (Lacépède) (Chandidae), and $P$. cf. mamaevi from the gills of the mottled spinefoot, Siganus fuscescens (Houttuyn) (Siganidae), were collected; these species are described herein.

\section{MATERIALS AND METHODS}

Fish hosts, Ambassis gymnocephalus and Siganus fuscescens, were obtained from local fishermen and kept alive in aerated fibre-glass tanks until examination for monogenoids within 24 hours of collection. Scientific and common names of hosts are those provided in FishBase (Froese and Pauly 2006). Fish were killed by a sharp blow to the head. Gill baskets were immediately excised and placed in vials containing hot $\left(60^{\circ} \mathrm{C}\right) 4 \%$ formalin to relax and fix the parasites. Gill baskets and the respective sediment from specimens of each host species were then pooled and shipped to the United States for study. Microcotylids were subsequently removed from the gills or sediment using a small probe under a dissecting microscope. Some specimens were mounted unstained in Gray and Wess medium for study of sclerotized parts; other specimens were stained with Gomori's trichrome or Genacher borax carmine (Kritsky et al. 1978, Humason 1979) and mounted in Canada balsam for observing internal anatomy. Illustrations were prepared with the aid of a camera lucida or microprojector. Measurements, all in micrometres, were made from unflattened stained specimens mounted in Canada balsam with a calibrated filar micrometer and are presented as the range followed by mean and number (n) measured in parentheses. Body length included that of the haptor; widths of the anterior and posterior clamps were obtained from clamps observed in dorsoventral view and situated within the first three terminal positions at each end of the haptor. Type and voucher specimens were deposited in the U.S. National Parasite Collection, Beltsville, Maryland, USA (USNPC), and the helminth collections of the Institute of Parasitology, Academy of Sciences of the Czech Republic, České Budějovice, Czech Republic (IPCAS); the School of Life Sciences, Zhongshan University, Guangzhou, China (ZSU); the British Museum of Natural History, London, UK (BMNH); and the Meguro Parasitological Museum, Tokyo, Japan (MPM). For comparative purposes, specimens, identified by Mamaev and Parukhin (1976) as Polylabris gerres from $S$. oramin and Terapon jarbua, were obtained as gifts from the helminth collection of the Far Eastern Research Centre, Vladivostok, Russia, through the courtesy of Dr. Boris Lebedev; these specimens were subsequently deposited in the USNPC (98583, 98584, respectively). The holotype of $P$. sigani (USNPC 71953) and specimens identified as Microcotyle mouwoi Ishii et Sawada, 1938 from the gills of $S$. sutor (Valenciennes) from the Kenyan Coast (BMNH 1992.7.28.89) and $S$. spinus (Linnaeus) from Guam (BMNH 1976.2.17.1-60) by A. Geets and W. Tobias, respectively, were also examined.

\section{RESULTS}

Class: Monogenoidea Bychowsky, 1937

Subclass: Heteronchoinea Boeger et Kritsky, 2001

Order: Mazocraeidea Bychowsky, 1937

Mi c r o c ot y lida e Taschenberg, 1879

Polylabris lingaoensis sp. $\mathrm{n}$.

Figs. 1-3

Description. Body lanceolate, 1,356 (1,130-1,597; $\mathrm{n}=$ 30) long; width at level of transverse portion of germarium $236(159-298 ; \mathrm{n}=35)$. Prohaptoral suckers elliptical to subcircular in outline, septate, open medially, with muscular anterior, posterior and lateral walls; septum extending diagonally across anterolateral half of sucker; sucker 41 (34-48; $\mathrm{n}=34)$ long, $43(37-50 ; \mathrm{n}=34)$ wide. Pharynx spherical, $34(27-42 ; n=32)$ in diameter; oesophagus relatively long, with bilateral pair of inconspicuous diverticula. Intestinal bifurcation at level of common genital pore; caeca blind, subequal in length, with lateral and medial transverse diverticula, extending to posterior limit of trunk. Haptor $583(478-735 ; \mathrm{n}=28)$ long, arising from ventral surface of trunk beginning at level of posterior testes, armed with 2 parallel subequal rows of 30-43 $(n=$ 40) microcotylid clamps each, with free posterior end usually recurved dorsally. Clamp bilaterally symmetrical; clamp sclerites include single medial sclerite having broad truncate dorsal end and ventral end with 2 diverging spinelike projections, paired anterolateral sclerites bent to form short dorsal and elongate ventral ends, and paired posterolateral sclerites flattened, lightly sclerotized, incorporated into muscular wall of clamp; largest clamps near midlength of each row; anterior clamp $43(39-48 ; n=28)$ wide; posterior clamp $36(33-40 ; \mathrm{n}=26)$ wide. Common genital pore midventral, surrounded by weak circular muscle; genital atrium unarmed. Five to 7 testes intercaecal in posterior half of body; each usually transversely elongate. Vas efferens not observed; vas deferens dilated immediately anterior to testes, then winding anteriorly along body midline to male copulatory organ; sigmoid seminal vesicle with thick wall, a simple dilation of vas deferens, lying just posterior to male copulatory organ; short ejaculatory duct enters base of male copulatory organ. Male copulatory organ conical, $39(34-45 ; \mathrm{n}=32)$ long, $27(22-33 ; \mathrm{n}$ $=34$ ) wide, consisting of inner tube and outer sheath; inner tube slightly expanded and with nearly parallel margins basally, narrowing before entering distal portion of outer sheath; tip of male copulatory organ flat, recurved dorsally. Pair of bilateral prostatic ducts uniting to form single common prostatic duct entering small circular pore on dorsal side of outer sheath of male copulatory organ. Germarium shaped as an interrogation mark, pretesticular, intercaecal, dorsal to vitelline ducts and uterus. Germarium originating on right side of trunk, extending anteri- 

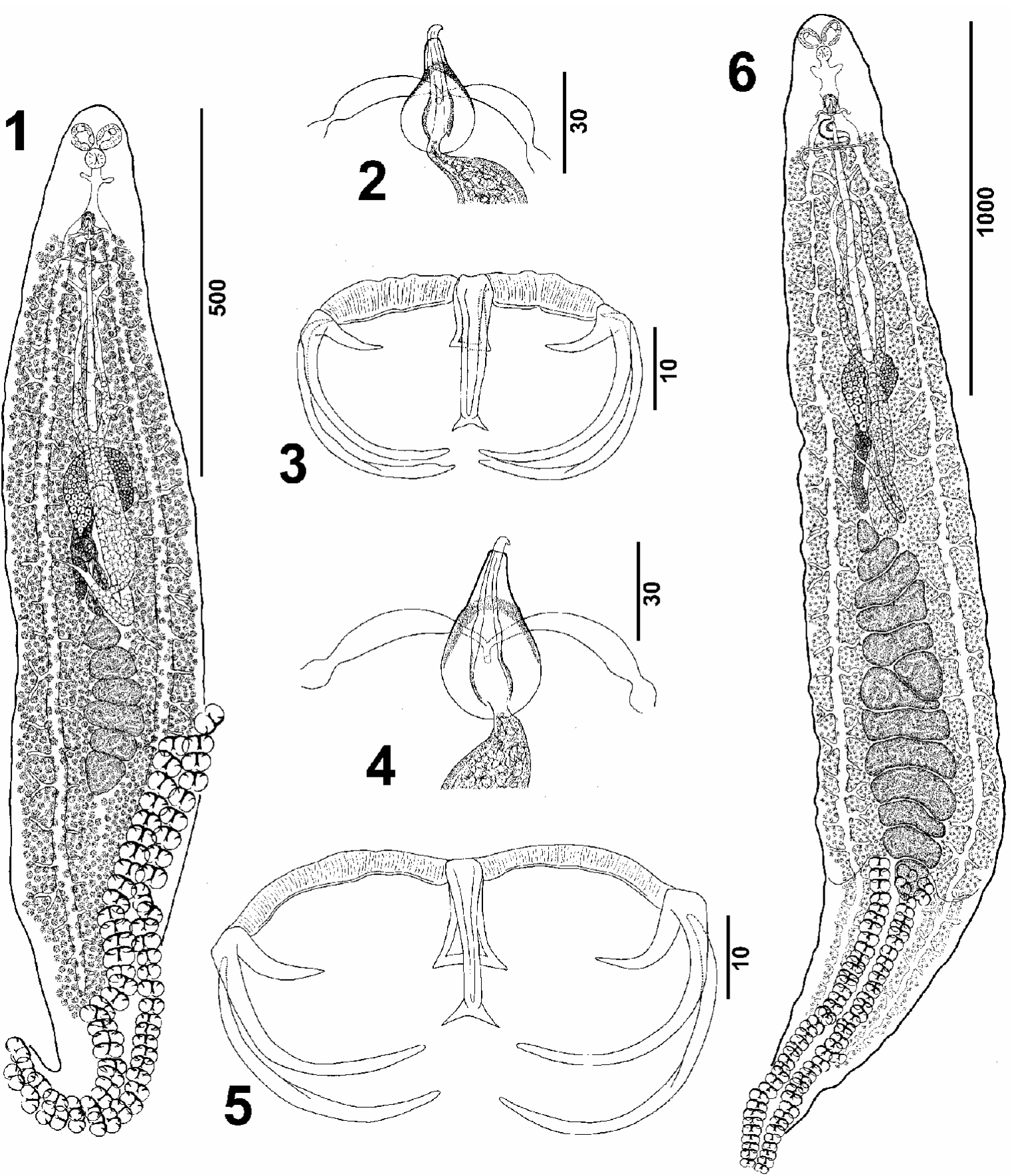

Figs. 1-6. Polylabris species from the Bay of Tonkin. Fig. 1. Whole mount of $P$. lingaoensis sp. n. (ventral, composite). Fig. 2. Male copulatory organ and distal portion of seminal vesicle of $P$. lingaoensis sp. n. (ventral). Fig. 3. Clamp of $P$. lingaoensis sp. n. (ventral). Fig. 4. Male copulatory organ and distal portion of seminal vesicle of $P$. cf. mamaevi (ventral, composite). Fig. 5. Clamp of $P$. cf. mamaevi (ventral). Fig. 6. Whole mount of $P$. cf. mamaevi (ventral, composite). Scale bars are in $\mu \mathrm{m}$.

orly before traversing intercaecal region to left side of trunk, then looping anteriorly back to right side of trunk and finally directed posteriorly where it narrows to form oviduct. Seminal receptacle saccate; oviduct receiving genitointestinal canal before vitellovaginal reservoir; genitointestinal canal uniting with right intestinal caecum; uterus arising from base of vitellovaginal reservoir, initially directed posteriorly, reflexed anteriorly, extending along body midline to genital atrium as relatively straight delicate tube dorsal to vitellovaginal reservoir, ventral to germarium and vas deferens; proximal portion of uterus usually filled with vitelline material and infrequently single oocyte. Vaginae unarmed, opening via single medioventral pore posterior to common genital pore; 2 bilateral vaginal ducts looping ventrodorsally around respective intestinal caeca, extending diagonally toward body mid- 
line, joining, then bifurcating into paired vitelline ducts; paired vitelline ducts uniting to form vase-shaped vitellovaginal reservoir near level of transverse portion of germarium. Vitelline follicles coextensive with intestinal caeca. Egg fusiform, with long distally tangled opercular filament and short abopercular filament with small flared tip.

$\mathrm{T}$ y $\mathrm{p}$ e $\mathrm{h}$ o s t : Bald glassy, Ambassis gymnocephalus (Lacépède) (Perciformes, Chandidae).

T y p e 1 o c a 1 i t y : Gulf of Tonkin, near Lingao, Hainan Province, China $\left(20^{\circ} 0\right.$ 'N, $\left.109^{\circ} 5^{\prime} \mathrm{E}\right)$ (15 January 2006).

Site of infection: Gills.

M a t e ri a 1 s t u di e d: Holotype, USNPC 98580; 38 paratypes, USNPC 98581, IPCAS M-423, ZSU HN 200600115 B-4, BMNH 2006.8.8.6-8, MPM 18831.

E t y $\mathrm{m}$ o $\log \mathrm{y}$ : The specific name refers to the type locality.

Remarks. Polylabris lingaoensis differs from P. sillaginae, $P$. australiensis, $P$. queenslandensis, $P$. williamsi and $P$. carnarvonensis in possessing a single midventral vaginal pore (latter 5 species reported to have 2 bilateral vaginal pores). Of species possessing a single midventral vaginal pore, $P$. lingaoensis differs from $P$. gerres, $P$. rhabdosargi, P. tubicirrus, $P$. maomao, $P$. acanthopagri, $P$. girellae, $P$. mamaevi and $P$. virgatarum by having fewer testes ( 5 to 7 in $P$. lingaoensis; numbers in the latter 8 species vary from 12 to 40, see Hayward 1996). The new species differs from $P$. acanthogobii (with 19-25 haptoral clamps per row) and $P$. japonicus (with 53-63 clamps per row) by having 30-43 clamps in each row of the haptor. Polylabris lingaoensis differs from $P$. kuhliae by having a dorsally recurved tip and an anteriorly tapered outer sheath of the male copulatory organ (tip straight and outer sheath heavily sclerotized with broad base having parallel proximal margins in $P$. kuhliae). Polylabris lingaoensis differs from $P$. angifer and $P$. halichoeres by possessing fewer testes (9-17 in $P$. angifer; $9-13$ in $P$. halichoeres) and by the number of clamps per row in the haptor (50-70 in $P$. angifer; 23-32 in $P$. halichoeres). Hayward (1996) was unsure of the accuracy of the report by Dillon et al. (1983) that $P$. sigani had paired ventro-lateral vaginal pores. Our examination of the holotype of $P$. sigani, the only known specimen of the species, confirmed that a single midventral vaginal pore is located slightly posterior to the male copulatory organ at the level of the distal tangle of the opercular filament of the intrauterine egg. Dillon et al. (1983) also reported that the holotype of $P$. sigani possesses 5 testes and that 30 clamps occurred in each haptoral row. Although all of these features are shared with $P$. lingaoensis, $P$. sigani is distinguished from this species by comparative size $(P$. sigani more than twice as long as $P$. lingaoensis) and the shape of the distal portion of the outer sheath of the male copulatory organ (subterminally constricted in P. sigani; constriction absent in P. lingaoensis).

Polylabris indica was considered a species inquirenda by Hayward (1996) because of the insufficient description provided by Gupta and Khullar (1968). In addition, the description of $P$. madagascarensis is also incomplete, is based on relatively few specimens, and morphometrics provided by Hayward (1996) for the species are similar to those of $P$. lingaoensis. While morphological details of these species are lacking, presence of 9-10 testes and the comparative morphology of the tip of the male copulatory organ serves to separate $P$. indica from $P$. lingaoensis. Comparative clamp size distinguishes $P$. madagascarensis from $P$. lingaoensis [largest clamps 61 (59-63) wide in $P$. madagascarensis; largest clamps near the middle of each clamp row in $P$. lingaoensis about $47(41-51 ; \mathrm{n}=26)$ wide]. Polylabris lingaoensis is the only species known from a member of the Chandidae.

\section{Polylabris cf. mamaevi Ogawa et Egusa, 1980}

Figs. 4-6

Syn.: Polylabris gerres of Mamaev and Parukhin (1976), not of Sanders (1944)

Description. Measurements of Mamaev and Parukhin's (1976) specimen from $S$. oramin (USNPC 98583) follow in brackets those of specimens from $S$. fuscescens, respectively. Body lanceolate, 2,811 $(1,837-4,122 ; n=20)$ $[3,711]$ long; width at level of transverse portion of germarium 446 (359-595; $n=22)$ [517]. Paired prohaptoral suckers elliptical in outline, septate, open medially, with muscular anterior, posterior and lateral walls; septum extending across anterolateral half of sucker; sucker 61 (49-74; $\mathrm{n}=23$ ) [76] long, 57 (49-72; $\mathrm{n}=23$ ) [67] wide. Pharynx spherical, $43(32-51 ; n=23)$ [46] wide; oesophagus with bilateral pair of inconspicuous diverticula near pharynx; intestinal bifurcation at level of male copulatory organ; caeca blind, with lateral and medial diverticula, subequal in length, extending to posterior limit of trunk. Haptor 446 (359-595; $\mathrm{n}=22)$ long, armed with 2 parallel subequal rows of 27-47 $(n=13)$ [37] micro-cotylid clamps each, arising from ventral surface of trunk at level of posterior testis, free posterior end usually curved dorsally. Clamp bilaterally symmetrical; medial sclerite with broad expanded dorsal end and ventral end with 2 diverging spine-like processes; paired anterolateral sclerites bent to form shorter dorsal and elongate ventral ends; paired posterolateral sclerites flattened, lightly sclerotized, incorporated into muscular wall of clamp; largest clamps in midregion of row; anterior clamp $58(51-68 ; \mathrm{n}=19)$ [51] wide; posterior clamp $38(35-44 ; \mathrm{n}=17)$ [40] wide. Common genital pore midventral at level of male copulatory organ, surrounded by circular muscles; genital atrium unarmed. Nine to 14 testes intercaecal in posterior half of trunk; each usually transversely elongate. Vas efferens not observed; vas deferens noticeably dilated immediately forward of anterior testis, winding anteriorly to seminal vesicle along body midline dorsal to vitellovaginal reservoir and uterus and ventral to germarium; sigmoid seminal vesicle with thick wall, immediately posterior to male copulatory organ, a simple dilation of vas deferens. Male copulatory organ conical, $53(46-60 ; n=20)$ long, $33(27-$ $37 ; n=19)$ wide, comprising inner tube and outer sheath; 
inner tube slightly expanded basally (or not), with nearly parallel margins, tapered within distal portion of outer sheath; tip of male copulatory organ flat, recurved dorsally. Pair of bilateral prostatic ducts, each with proximal bulbous expansion, uniting to form common prostatic duct before entering male copulatory organ through small circular pore on dorsal surface of outer sheath. Germarium pretesticular, intercaecal, shaped as interrogation mark with ends on right side of trunk; proximal end directed anteriorly, then looping to left side of trunk and back to right side, and finally extending posteriorly to give rise to narrow oviduct. Seminal receptacle saccate; oviduct receiving gastrointestinal canal, vitellovaginal reservoir before ending at inconspicuous ootype; ootype surrounded by weakly staining Mehlis' gland; uterus relatively straight, extending anteriorly along body midline ventral to other reproductive organs except dorsal to vitellovaginal reservoir, opening into genital atrium. Oocytes and vitelline material intermittently present in oviduct, ootype and/or proximal uterus. Vitellovaginal reservoir vaseshaped, lying ventral to germarium, vas deferens and uterus, receiving vitelline ducts at level of transverse portion of germarium. Vaginal pore midventral, slightly posterior to common genital pore; bilateral vaginae unarmed, ventrodorsally looping respective intestinal caecum before joining along midline and subsequently bifurcating to form vitelline ducts. Vitelline follicles coextensive with intestinal caeca. Egg fusiform, 208 (194-218; n = 3) long, 64 $(55-76 ; \mathrm{n}=3)$ wide; opercular filament long and distally tangled; abopercular filament short, with small flared end.

$\mathrm{Hos} t$ and 1 o c a 1 it y: Mottled spinefoot, Siganus fuscescens (Houttuyn) (Perciformes, Siganidae); Gulf of Tonkin, near Lingao, Hainan Province, China $\left(20^{\circ} 0{ }^{\prime} \mathrm{N}, 109^{\circ} 5^{\prime} \mathrm{E}\right)(11$ July 2004, 15 January 2006).

Site of infection: Gills.

Pre vi o u s r e c o r d s : Brownspotted spinefoot, Siganus stellatus (Forsskål) (Siganidae); white-spotted spinefoot, $S$. oramin (Bloch et Schneider) [valid name, S. canaliculatus (Park)] (Siganidae); Siganus sp. (Siganidae); jarbua terapon, Terapon jarbua (Forsskål) (Terapontidae): (all) Gulf of Masira, Arabian Sea, Oman (Mamaev and Parukhin 1976).

M a t e r i a 1 s t u d i e d : 25 vouchers from $S$. fuscescens, USNPC 98585, 98586, IPCAS M-429, BMNH 2006.8.8.910, ZSU HN 20060115 A1-4, MPM 18830; voucher (from $S$. oramin), USNPC 98583.

Remarks. Assignment of the parasite specimens from Siganus fuscescens to P. mamaevi is problematical. Three nominal species of Polylabris have been recorded from siganid fishes from the Indo-Pacific Region, i.e., P. $m a-$ maevi, $P$. sigani, and $P$. virgatarum. Mamaev and $\mathrm{Pa}-$ rukhin (1976) recorded $P$. gerres (Sanders) from three different hosts, S. stellatus, S. oramin and Terapon jarbua, from the Bay of Masira, Oman and redescribed the species based on specimens from $S$. stellatus. Ogawa and Egusa (1980) felt that $P$. gerres sensu Mamaev and Parukhin (1976) represented an unnamed species, to which they assigned the epithet $P$. mamaevi. Through the courtesy of Dr. Boris Lebedev, we had the opportunity to examine one of Mamaev and Parukhin's specimens from S. oramin (USNPC 98583). This specimen was clearly conspecific with those from $S$. fuscescens from the Bay of Tonkin. However, Ogawa and Egusa (1980) did not provide a new description of $P$. mamaevi, basing their new name on the description provided by Mamaev and Parukhin (1976), and they were unsure whether or not Mamaev and Parukhin's forms from $S$. oramin and T. jarbua were conspecific with $P$. mamaevi from $S$. stellatus.

Hayward (1996) indicated that P. mamaevi from Siganus spp. may be a junior synonym of $P$. virgatarum but did not propose synonymy in absence of specimens from the latter's type host, $S$. virgatus. The inadequate original description of $P$. virgatarum by Tubangui (1931), the subsequent destruction of the type specimens (see Hayward 1996), and the lack of new microcotylid material from $S$. virgatus also prevented our consideration of assignment of present specimens from $S$. fuscescens to this species. Finally, P. sigani was described by Dillon et al. (1983) from the gills of $S$. oramin in Western Australia, and Diamant et al. (1999) reported P. sigani from S. rivulatus collected from the northern Gulf of Eilat of the Red Sea. Although some potentially important differences were observed between the holotype of $P$. sigani and present specimens from $S$. fuscescens, i.e., morphology of the male copulatory organ (see Hayward 1996), it is uncertain whether this dissimilarity represents specific difference, intraspecific variation or artifact produced when the respective specimens were prepared for mounting. It should be noted that $P$. sigani is based on a single specimen and as a result intraspecific variation is unknown.

Further complicating species assignment is that the hosts, $S$. oramin (= S. canaliculatus) and $S$. fuscescens, are difficult to differentiate morphologically and their respective geographic ranges overlap in the Indo-Pacific Region (Woodland 1990). Hayward (1996) considered the two species to be synonyms ( $S$. fuscescens having priority), although Woodland (1990) considered them to be distinct. Thus, the possibility of previous error in host identification further perplexes species assignment of their parasites. Because the present specimens of Polylabris most closely match the description presented by Mamaev and Parukhin (1976) for the form from S. stellatus, and they are obviously conspecific with the specimen from $S$. oramin from Oman, we tentatively assign the parasites from $S$. fuscescens to $P$. cf. mamaevi, while recognizing that further taxonomic revision may be necessary when parasite specimens from other siganid hosts, particularly $S$. stellatus and S. virgatus, become available for study.

Ko and Chan (2002) reported Microcotyle sp. from the gills of $S$. fuscescens and Mylio latius, a misspelling of $M$. latus (= Acanthopagrus latus), from Hong Kong. Their description and illustration of the species from $S$. fuscescens, suggests that the specimens from Hong Kong are conspecific with those of the species from the Bay of 
Tonkin, while those from A. latus likely represent another undetermined species of Polylabris.

Martens and Moens (1995) and Geets et al. (1997) identified Microcotyle mouwoi Ishii et Sawada, 1938 from the gills of $S$. sutor from the Kenyan coast. We examined 3 specimens identified by A. Geets (BMNH 1992.7.28.89) and found no morphological basis for separating these specimens from $P$. cf. mamaevi, suggesting that the reports of M. mouwoi from S. sutor by Martens and Moens (1995) and Geets et al. (1997) represent $P$. cf. mamaevi. All this suggests that synonymy of $M$. mouwoi of Ishii and Sawada (1938) with $P$. cf. mamaevi is a possibility. Unfortunately, the type specimens of $M$. mouwoi apparently have been lost or destroyed. Attempts to locate them in the MPM and the University Museum of the University of Tokyo were unsuccessful (J. Araki, pers. comm.; Shimazu and Araki 2006), and as a result, we are reluctant at this time to synonymize the two species. It is worth mentioning that we also examined specimens identified as $M$. mouwoi from $S$. spinus and collected off Guam (BMNH 1976.2. 17.1-60) by Tsuda et al. (1976) [specimens deposited in the BMNH by W.J. Tobias] that also could not be morphologically differentiated from current specimens of $P$. cf. mamaevi, further supporting a hypothesis that all (or most) microcotylids from Siganus spp. represent a single species.

Through the courtesy of Dr. Lebedev, we had the opportunity to examine a single specimen of $P$. gerres sensu Mamaev and Parukhin (1976) from T. jarbua (Terapontidae) (USNPC 98584). This helminth is not conspecific with $P$. mamaevi from $S$. stellatus or with $P$. cf. mamaevi from $S$. fuscescens and may represent an undescribed species of Polylabris. Although many important diagnostic features could not be determined which precluded description of the species, the specimen differs from $P$. cf. mamaevi by the morphology of the male copulatory organ, which has a comparatively long inner tube proximally extending beyond the ventral margin of the outer sheath and distally protruding from the outer sheath by its straight truncate tip.

\section{DISCUSSION}

In his revision of the genus, Hayward (1996) recognized 17 species of Polylabris based almost solely on comparative morphology of the male copulatory organ and used the number of vaginal pores (vaginae) and characters of the male copulatory organ for identification in his key to the species. Hayward (1996) also suggested that certain characters, including the presence of a constriction near the proximal end of the male accessory glands and the anterior extent of clamps in the body were taxonomically unreliable because of intraspecific variation and potential introduction of artifacts during fixation. He indicated that the numbers of clamps and testes could become useful for species identification if more data becomes available.
While variability in the numbers of clamps and testes was also detected in current specimens of $P$. lingaoensis and $P$. cf. mamaevi, measurements and morphological features of the male copulatory organ were also inconstant among conspecific specimens obtained from respective hosts. Present findings suggest that no one structure is sufficient for species discrimination and that all characters, including those of the male copulatory organ, clamps, testes and other organs, should be considered when identifying species of Polylabris.

In this study, the host range of species comprising Polylabris has been extended to include a member of the Chandidae. Also, an apparent undescribed species of Polylabris (voucher specimen, USNPC 98582) occurring on the gills of Rachycentron canadum (Linnaeus) (Rachycentridae) off the coast of Kuwait was observed by O. Sey and D.C. Kritsky (unpublished); this record represents the 14th family of fishes serving as hosts for Polylabris spp. Some species of Polylabris show a high level of host specificity by being restricted to one host species, while those occurring on multiple host species are limited to fishes with relatively close phylogenetic relationships, i.e., their hosts are either congeneric or limited to a single perciform family. This pattern of host ranges suggests a low probability of cospeciation among Polylabris spp., with adaptive modes of speciation dominating the evolutionary history and development of the genus. Boeger et al. (2003) observed similar patterns of host-parasite relationships for the viviparous gyrodactylids whose diversification and evolutionary history was shown to be dominated by host-switching events followed by isolation and speciation. These authors identified several plesiomorphic and apomorphic characteristics of viviparous gyrodactylids that apparently allowed the historical development of the group. Assuming that the majority of species described in Polylabris are valid, i.e., they do not represent intraspecific variation caused by ecological (host and/or environmental) influences, a coevolutionary analysis should show that host-parasite relationships within Polylabris are also minimally a result of cospeciation but dominated by dispersal (host-switching) events followed by speciation. However, morphological features distinguishing species of Polylabris are minimal and unlikely sufficient to provide the data base to conduct rigorous coevolutionary studies. Applying phylogenetic systematics to molecular data might be the best means of determining the evolutionary history of the group.

Acknowledgements. The authors gratefully acknowledge our dear late friend, Boris Lebedev (Far East Division, Russian Academy of Sciences) for providing the gift of two specimens of $P$. gerres (sensu Mamaev and Parukhin, 1976) and for allowing us to deposit them in the USNPC. Eric Hoberg and Pat Pilitt (USNPC) and Eileen Harris (BMNH) provided loans of microcotylid specimens from their respective museums. 


\section{REFERENCES}

BOEGER W.A., KRITSKY D.C., PIE M.R. 2003: Context of diversification of the viviparous Gyrodactylidae (Platyhelminthes, Monogenoidea). Zool. Scr. 32: 437-448.

Diamant A., Banet A., PAparna I., v. Westernhagen H., Broeg K., Kruener G., Koerting W., Zander S. 1999: The use of fish metabolic, pathological and parasitological indices in pollution monitoring. II. The Red Sea and Mediterranean. Helgol. Mar. Res. 53: 195-208.

DILlON W.A., HARGIS W.J. JR., HARRISES A.E. 1983: Monogeneans from the southern Pacific Ocean. Polyopisthocotyleids from Australian fishes. The subfamilies Polylabrinae and Microcotylinae. Zool. Zh. 62: 821-828. (In Russian.) Translation Series 31, Virginia Institute of Marine Science, College of William and Mary, Gloucester Point, Virginia, March, 1985.

Froese R., PAuly D. (Eds.) 2006: FishBase. World Wide Web electronic publication, available at www.fishbase.org. Accessed 16 June 2006

GeETS A., COENE H., Ollevier F. 1997: Ectoparasites of the whitespotted rabbitfish, Siganus sutor (Valenciennes, 1835) off the Kenyan Coast: distribution within the host population and site selection on the gills. Parasitology 115: 69-79.

GUPTA N.K., KHULlaR M. 1968: Studies on the monogenetic trematodes of some Indian marine food fishes. Res. Bull. Punjab Univ. 19: 47-69.

HAYWARD C.J. 1996: Revision of the monogenean genus Polylabris (Microcotylidae). Invertebr. Taxon. 10: 995-1039.

HUMASON G.L. 1979: Animal Tissue Techniques, 4th ed. W.H. Freeman and Company, San Francisco, California, 661 pp.

ISHII N., SAWADA T. 1938: Studies on the ectoparasitic trematodes. In: Livro Jubilar Prof. Travassos, Rio de Janeiro, Brasil, III, pp. 231-243.

Ko R.C., Chan S.-W. 2002: A preliminary study on the parasite fauna of three common marine fish of Hong Kong (Siganus fuscescens, Sebasticus marmoratus, Epinephelus akaara). Department of Zoology, The University of Hong Kong Occasional Publication, $71 \mathrm{pp}$.

KRITSKY D.C., LEIBY P.D., KAYTON R.J. 1978: A rapid stain technique for the haptoral bars of Gyrodactylus species (Monogenea). J. Parasitol. 64: 172-174.

MAMAeV Yu.L., PARUKHIN A.M. 1976: The genus Polylabris Euzet et Cauwet, 1976 and some closely related species of micro- cotylids (Monogenoidea: Microcotylidae). Parazitologiya (Leningrad) 10: 245-254. (In Russian.)

MARTENS E., MOENS J. 1995: The metazoan ecto- and endoparasites of the rabbitfish, Siganus sutor (Cuvier \& Valenciennes, 1835) of the Kenyan coast. I. Afr. J. Ecol. 33: 405-416.

Mollaret I., JAMIESON B.G.M., JUSTINE J.-L. 2000: Phylogeny of the Monopisthocotylea and Polyopisthocotylea (Platyhelminthes) inferred from 28S rDNA sequences. Int. J. Parasitol. 30: 171-185.

OGAWA K., EGUSA S. 1980: Two species of microcotylid monogeneans collected from black sea bream, Acanthopagrus schlegeli (Bleeker) (Teleostei: Sparidae). Jpn. J. Parasitol. 29: 455-462.

SANDERS D.F. 1944: A contribution to the knowledge of the Microcotylidae of Western Australia. Trans. R. Soc. S. Aust. 68: 6781.

SANTOS C.P., SOUTO-PADRÓN T., LANFREDI R.M. 1996: Atriaster heterodus (Lebedev and Paruchin, 1969) and Polylabris tubicirrus (Paperna and Kohn, 1964) (Monogenea) from Diplodus argenteus (Val., 1830) (Teleostei: Sparidae) from Brazil. J. Helminthol. Soc. Wash. 63: 181-187.

SHIMAZU T., ARAKI J. 2006: A list of the helminth parasite specimens deposited in the Department of Zoology, the University Museum, the University of Tokyo. In: R. Ueshima, (Ed.), Catalogue of invertebrate collection deposited in the Department of Zoology, the University Museum, the University of Tokyo. The University Museum, the University of Tokyo Material Reports No. 62, pp. 151-161.

TSUDA R.T., TOBIAS W.J., BRYAN P.G., FitZGERALD W.J. JR., KAMI H.T., IKEHARA I.I. 1976: Studies on the genus Siganus (Rabbitfish) in Guam waters. Final Report. University of Guam Marine Laboratory Technical Report No. 29, pp. 58-93.

TUBANGUi M.A. 1931: Trematode parasites of Philippine vertebrates, IV. Ectoparasitic flukes from marine fishes. Philipp. J. Sci. 45: 109-117.

WANG W., ZHANG H. 1998: A new species of the genus Polylabris (Mazocroeidea [sic]: Microcotylidae). J. S. China Norm. Univ. 1998: 83-86. (In Chinese.)

WoODLAND D.J. 1990: Revision of the fish family Siganidae with descriptions of two new species and comments on distribution and biology. Indo-Pac. Fish. (No. 19), 136 pp. 